\title{
Coefficient of Variance
}

National Cancer Institute

\section{Source}

National Cancer Institute. Coefficient of Variance. NCI Thesaurus. Code C63904.

The ratio of standard deviation to mean, expressed as a percentage or fraction. 